\title{
PARATYLOTROPIDIA BEUTENMUELLERI SP. NOV.
}

BY ALBERT P. MORSE, WELLESLEY, MASS.

FACIAL costa shallowly sulcate, narrowed above at meeting with vertex. Vertex sub-acute in profile, plane above, its anterior margins angulate over shallow foveolae open below to the antennal fossae. Pronotum evenly tectiform above; the sides plane, meeting dorsum at an angle less pronounced posteriorly; lateral carinae straight, evenly divergent, obsolete near hind margin. Lateral lobes smooth above, longitudinally rugulose below on prozona, coarsely punctate on metazona, flavescent save for narrow fuscous border below lateral carinae. Prosternal spine pyramidal with rounded apex. Metepisternum with distinct ruga. Tegmina short, nearly as broad as long $(4 \times 5 \mathrm{~mm}$.), truncate, apex broadly rounded, dorsal field broad, scaircely angulate with lateral. Hind femora of moderate size, olivaceous, rufo-flavescent above. Valves of ovipositor strongly exserted, slender, ventro-lateral teeth absent, dorso-lateral edges sinuous, without serrations. Cerci small, triangular, one-and-one-third times as long as wide, acutely pointed. Abdomen keeled above.

Ferruginous brown above, varied with flavescent on the abdomen; flavescent beneath and on sides of head, pronotum, and metepisterna. Hind femora olivaceous; hind tibiae deep red.

Length of body: 27.5; hind fem.: 13.6. Pronotum: prozona, 4, metazona, 3; width of metazona, 5 . Tegmina: length, 5 ; width, $4 \mathrm{~mm}$.

One female. Valley of Black Mt., N. C., Aug. 30, 1906. W. Beutenmüller.

This is a smaller species than brunneri, having the general appearance and coloration of several of the brachypterous species of Melanoplus inhabiting the same district. It lacks the conspicuous flavescent lateral stripes on the head, pronotum and tegmina characteristic of brunneri, from which it also differs markedly in the structure of those members. Discovery of the male is awaited with interest.

This species, though differing much from brunneri, is doubtless congeneric with it and is especially interesting as being the eastern representative of the genus. Brunneri occurs locally from Texas to Dakota, being apparently restricted to the undergrowth of open, rather dry, woodlands. It is probable that the present species will be found to have a similar habitat in the East. I take great pleasure in proposing for it the name of its discoverer, in honor of his researches upon the insect fauna of the southern Appalachians. 

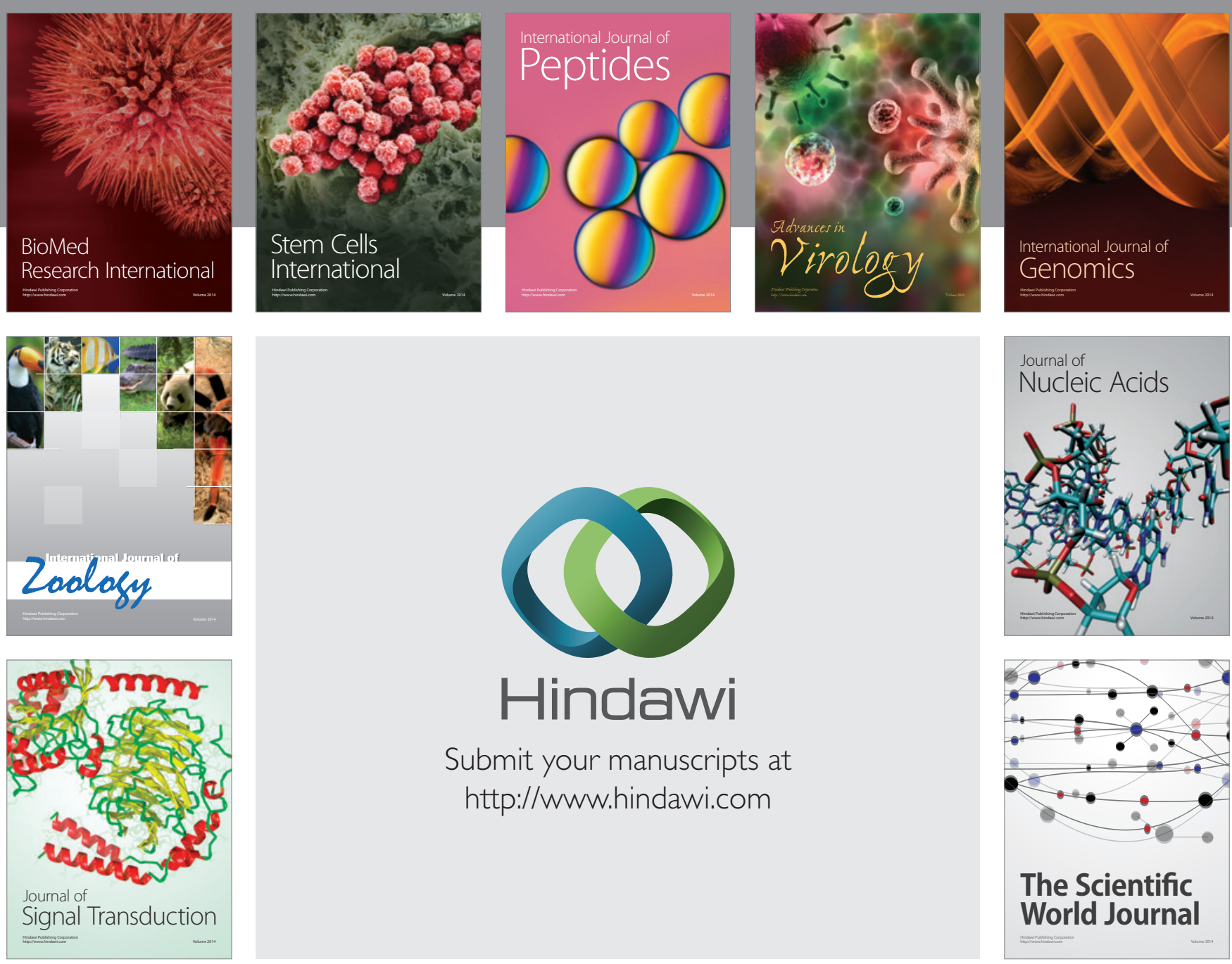

Submit your manuscripts at

http://www.hindawi.com
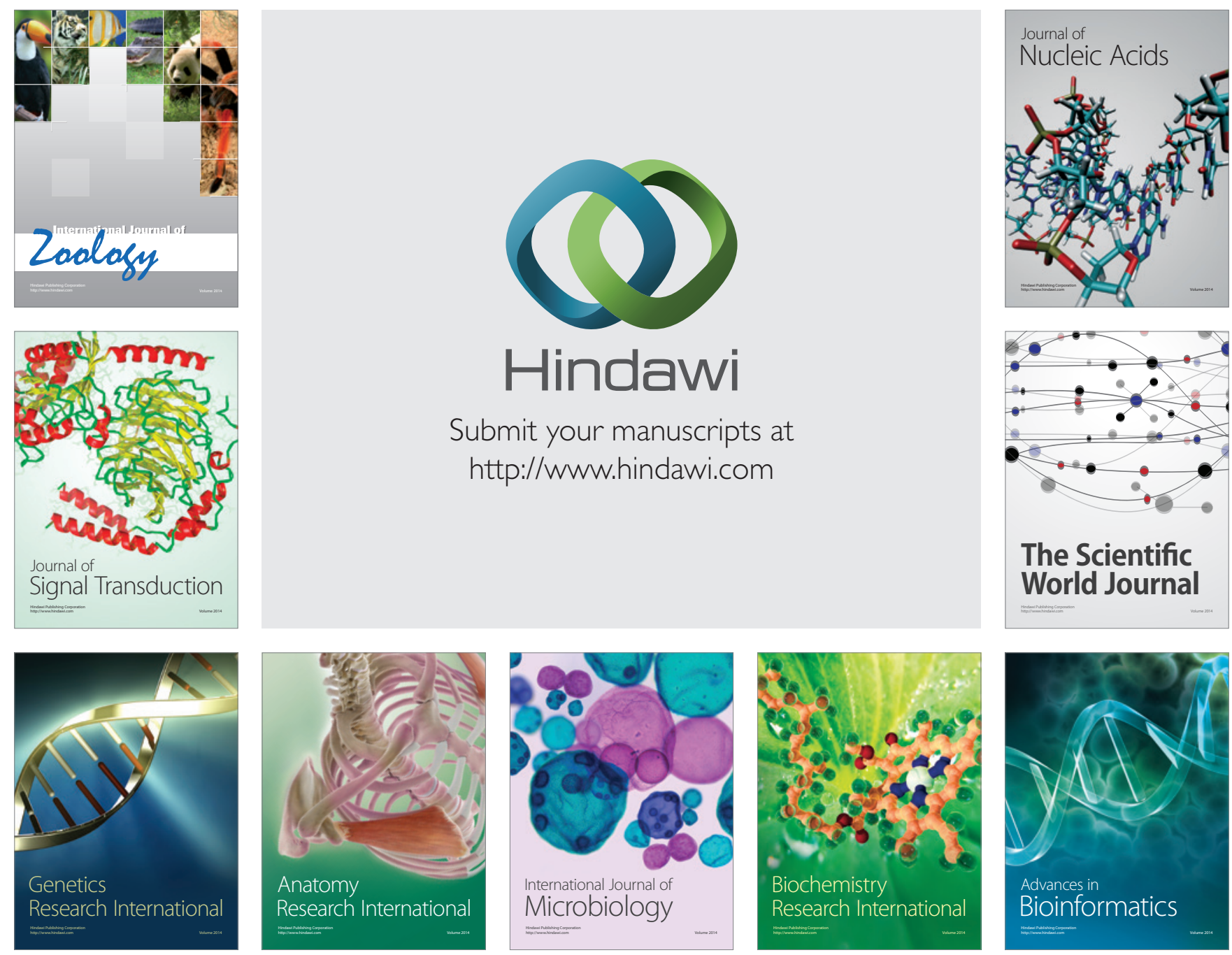

The Scientific World Journal
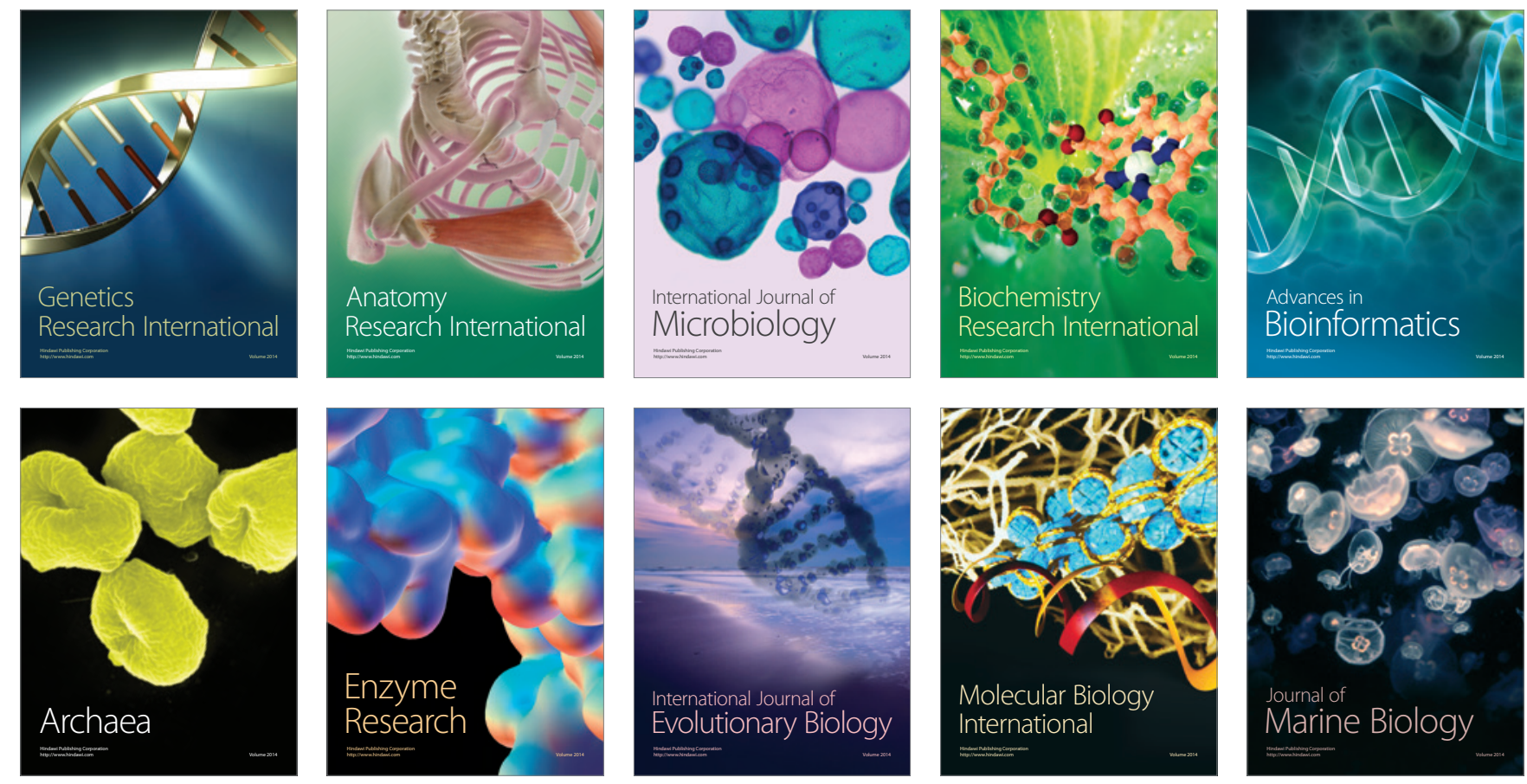